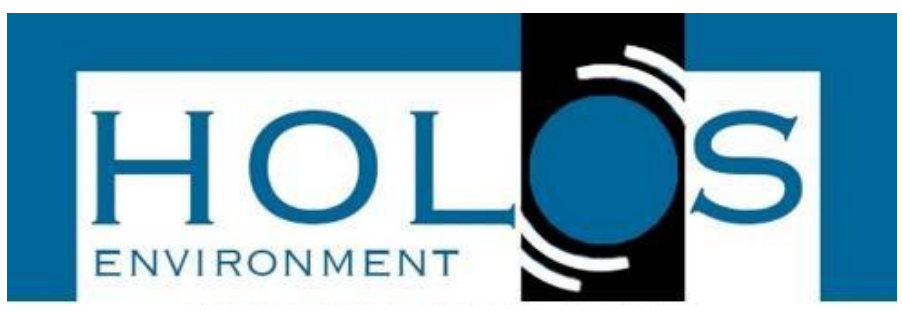

\title{
AVALIAÇÃO DA COMPOSIÇÃO E DA LIXIVIAÇÃO DE PRATA DE PELÍCULAS RADIOGRÁFICAS DE USO ODONTOLÓGICO
}

\section{EVALUATION OF SILVER COMPOSISTION AND LEACHING OF RADIOGRAFIC FILE FOR DENTISTRY USE}

\author{
Wilson Costa ${ }^{1}$; Alana Deduck Cicilinski ${ }^{1}$; André Vitor Chaves Andrade ${ }^{1}$
}

Artigo recebido em: 31/03/2020 e aceito para publicação em: 16/06/2020.

DOI: http:/dx.doi.org/10.14295/holos.v20i3.12383

\begin{abstract}
Resumo: Na busca de diagnóstico ou no acompanhamemto de determinados procedimentos na área odontológica é comum o uso de radiografias, cujas películas são produzidas através da adição de um sal de prata numa gelatina depositada sobre uma lâmina de poliéster. O objetivo deste trabaho foi de avaliar a composição de películas radiográficas de uso odontológico (periapicais) através de difração de raios $X$ (DRX), microscopia eletrônica de varredura de efeito de campo (FEG) e espectroscopia de energia dispersiva de raios $X$ (EDS) e, determinar a concentração de prata via espectroscopia de absorção atômica nos extratos obtidos através da utilização método de Tessier. Através do EDS, verificou-se a presença de diversos elementos, sendo prata o mais abundante quando a película é submetida aos processos de revelação e fixação. Pela difração de raios $X$, detectou-se prata metálica nas películas reveladas e fixadas e, nos extratos obtidos através da utilização do método de Tessier, encontrou-se prata em concentrações acima daquelas permitidas em efluentes de acordo com a resolução CONAMA 430/11.
\end{abstract}

Palavras-chave: Prata. Radiografia. Tessier.

\begin{abstract}
When searching for a diagnosis or following certain procedures in the dentistry field, it is common to use radiographs, whose films are produced by adding a silver salt to a gelatin deposited on a polyester blade. The objective of this work was to evaluate the composition of radiographic films for dental use (periapical) through X-ray diffraction (XRD), field effect scanning electron microscopy (FEG) and X-ray dispersive energy spectroscopy (EDS) and, determine the silver concentration via atomic absorption spectroscopy in the extracts obtained using the Tessier method. Through the EDS, the presence of several elements was verified, with silver being the most abundant when the film is submitted to the development and fixation processes. By X-ray diffraction, metallic silver was detected in the revealed and fixed films and, in extracts obtained through the use of the Tessier method, silver was found in concentrations above those allowed in effluents according to CONAMA resolution 430/11.
\end{abstract}

Keywords: Silver. Radiography. Tessier.

\section{INTRODUÇÃO}

O uso dos raios $X$ é parte integrante da Odontologia clínica, em que, para a maioria dos pacientes, alguma forma de exame radiográfico se faz necessário. Como resultado, as

\footnotetext{
1 Universidade Estadual de Ponta Grossa (UEPG), Ponta Grossa, PR. E-mail: (wcosta@uepg.br, alanastrike@hotmail.com, avcandrade@gmail.com)
} 
radiografias são frequentemente referenciadas como principal meio auxiliar para o diagnóstico clínico (WAITES, 2007).

A denominação intrabucal é empregada para as tomadas radiográficas nas quais o filme é colocado no interior da cavidade bucal no momento da obtenção das radiografias (FREITAS, VAROLI, TORRES, 2004). A radiografia periapical representa a técnica intraoral designada para mostrar os dentes individualmente e os tecidos em torno do ápice (WAITES, 2007).

Como base e suporte do filme radiográfico utiliza-se o poliester numa espessura de $0,2 \mathrm{~mm}$. Ele é transparente e geralmente colorido de azul. Sobre este material de suporte se sobrepõe, nos dois lados, uma camada adesiva extremamente fina composta de material obtido de gelatina e plástico, e que assegura a aderência das camadas da emulsão sensíveis à luz na base de poliester (PASLER, 1999).

A gelatina que compõe essa emulsão é impregnada de pequenos cristais de haletos de prata; o tamanho dos grãos é muito importante, pois afeta a qualidade da radiografia. Sobre este nível fotossensível, sobrepõe-se uma camada de proteção, a qual é constituída por uma fina camada de gelatina e apresenta a função de proteger a emulsão do contato com forças mecânicas (ALVARES, TAVANO, 2009).

O filme é protegido externamente por um envoltório de plástico ou papel, e internamente é colocado num envelope de papel preto e opaco; logo atrás é encaixada uma fina lâmina de chumbo com a finalidade de evitar perdas na qualidade da imagem (PASLER, 1999).

Os grânulos de prata que compõe a emulsão geralmente são obtidos da reação entre nitrato de prata e brometo de potássio, produzindo o brometo de prata. Esta reação é representada pela equação 1 .

$\mathrm{AgNO}_{3}+\mathrm{KBr} \rightarrow \mathrm{AgBr}+\mathrm{KNO}_{3}$

Ao serem atingidos pelos fótons de radiação $X$, estes cristais de brometo de prata são ionizados e constituem uma imagem denominada latente (ALVARES, TAVANO, 2009). Segundo KUYA (1993), a ação dos raios X sobre um haleto de prata pode ser representada pela equação 2 .

$\mathrm{AgX}+\mathrm{hv} \rightarrow(\operatorname{AgX})^{*}$ 
Processamento é o termo genérico usado para descrever a sequência de eventos requisitados para converter a imagem latente invisível, contida na emulsão do filme sensibilizado, em uma imagem visível em preto e branco (WAITES, 2007).

Os estágios de conversão consitem na utilização inicial de uma solução reveladora que apresenta várias substâncias químicas, todas com funções definidas, como elon e hidroquinona que são redutores convertendo cristais de halogenatos de prata da emulsão que foram sensibilizados em prata negra, agentes aceleradores ou alcalinizantes como $o$ carbonato ou hidróxido de sódio que promovem o amolecimento da gelatina da emulsão, sulfito de sódio que é um agente oxidante, evitando a oxidação da solução reveladora e o brometo de potássio que impede a ação dos redutores sobre os sais de prata não expostos aos raios $X$ (FREITAS, ROSA, SOUZA, 2004).

Após a lavagem, a película é mergulhada numa solução fixadora, cuja função é dissolver os sais de prata que não foram expostos aos raios $\mathrm{X}$ e endurecer a gelatina para que o filme apresente resistência à abrasão e seque rapidamente. $O$ componente principal do fixador é o hipossulfito de sódio (tiossulfato de sódio). O antioxidante é o mesmo do revelador (sulfito de sódio). A presença de ácido acético é necessária para neutralizar os componentes alcalinos do revelador. $O$ alumen de potássio está presente com o objetivo de evitar o amolecimento da gelatina (FREITAS, ROSA, SOUZA, 2004).

O reagente principal da solução fixadora é o tiossulfato de sódio, que reage com o haleto de prata que não foi decomposto pelos raios $\mathrm{X}$, formando tiossulfato de prata, solúvel. A reação que ocorre é representada pela equação 3 (LEE, 1999).

$\mathrm{AgBr}+2 \mathrm{Na}_{2} \mathrm{~S}_{2} \mathrm{O}_{3} \rightarrow \mathrm{Na}_{3}\left[\mathrm{Ag}\left(\mathrm{S}_{2} \mathrm{O}_{3}\right)_{2}\right]+\mathrm{NaBr}$ equação (3)

Alvares e Tavano (2009) citam composições para reveladores e fixadores e elas são iguais a aquelas citadas anteriormente. Em trabalhos de outros autores (WAITES, 2007; PASLER, 1999) e em rótulos de produtos comerciais são encontradas composições diferentes mas, se observa sempre a presença de hidroquinona nos reveladores e tiossulfato de sódio nos fixadores.

Pelo exposto, se observa que as películas radiográficas reveladas apresentam quantidades variáveis de prata. A contribuição deste estudo reside na avaliação da composição inorgânica destas películas, as caracterizações estruturais que indicam por sua vez as formas de possíveis associações e o potencial de mobilização da prata a partir de método de Tessier e colaboradores (1979). 


\section{METODOLOGIA}

\subsection{Películas radiográficas}

Foram utilizadas as da marca Agfa Dentus E-Speed de tamanho $3 \times 4 \mathrm{~cm}$, expostas a radiação oriunda do aparelho de raios X GNATUS TIMEX-70, operando a $70 \mathrm{kV}$ e $7 \mathrm{~mA}$ pelo tempo de $1 \mathrm{~s}$. Quando reveladas, tal procedimento foi realizado por $1 \mathrm{~min}$., seguida de lavagem por $5 \mathrm{~s}$. A fixação foi feita por 1 min., seguida de lavagem em água corrente pelo período de $15 \mathrm{~s}$ e secagem ao ar. Obteve-se três tipos de película: revelada e fixada (RF), fixada $(F)$, revelada, fixada e submetida ao ácido nítrico concentrado em ebulição pelo tempo $15 \mathrm{~min}$.(RFH). Os produtos utilizados na revelação e fixação foram da marca Carestream Dental.

\subsection{Caracterização}

2.2.1 Microscopia eletrônica de varredura por efeito de campo (FEG) e espectroscopia de energia dispersiva de raios $X$ (EDS)

A avaliação morfológica das películas foi realizada por meio de microscopia eletrônica de varredura por efeito de campo (FEG), em um microscópio da marca TESCAN, modelo MIRA. As imagens foram obtidas no modo de elétrons secundários com magnificação de 10.000 vezes. A composição química foi estudada por meio da espectroscopia de energia dispersiva de raios $X$ (EDS), tendo as concentrações dos elementos expressas em termos de porcentagem em massa.

\subsubsection{Difração de raios $X$}

Os dados de difração de raios $X$ foram coletados em um difratômetro SHIMADZU XRD-6000, operando com tubo de cobre a $40 \mathrm{kV}$ e $30 \mathrm{~mA}$. Foram utilizadas fendas de divergência e espalhamento de $1^{\circ}$ e de recepção de $0,30 \mathrm{~mm}$. Os dados foram coletados no modo de varredura contínua com velocidade de $1^{\circ} \mathrm{min}^{-1}$ no alcance de $10^{\circ}$ a $100^{\circ}$. A identificação das possíveis fases cristalinas foi realizada por comparação com simulações de padrões de difração a partir de fichas de informação cristalográfica obtidas do banco de dados Crystallography Open Database. 


\subsection{Mobilidade da prata}

Para a avaliar a mobilidade da prata, foi realizada a extração sequencial segundo método de Tessier e colaboradores (1979), conduzidas em triplica para $1 \mathrm{~g}$ de películas reveladas e fixadas que foram cortadas em pequenas frações. As soluções empregadas são de reagentes seletivos, isto é, capazes de extrair para a fase líquida os elementos presentes em tipos específicos de fases, ou frações, por reações de dupla troca iônica, oxiredução e dissolução (BOSSO, ENZWEILER, 2008). Nesta extração a prata foi lixiviada na forma em que pode ser removidos em $\mathrm{pH}=7,0 ; \mathrm{pH}=5,0$; aplicação de um redutor (R) e oxidante (O). As concentrações deste metal nos lixiviados foi determinada por espectroscopia de absorção atômica com atomização por chama utilizando o aparelho Varian Spectra AAS - 240FS.

\section{RESULTADOS E DISCUSSÃO}

\subsection{Microscopia eletrônica de varredura por efeito de campo (FEG)}

Na Figura 1, tem-se respectivamente as micrografias obtidas através da FEG das películas reveladas e fixadas $(\mathrm{RF})$, fixadas $(\mathrm{F})$ e revelada, fixada e submetida ao ácido nítrico concentrado em ebulição (RFA) na escala de $2 \mu \mathrm{m}$

Figura 1- FEG das películas radiográficas $R F, F$ e $R F H$ respectivamente

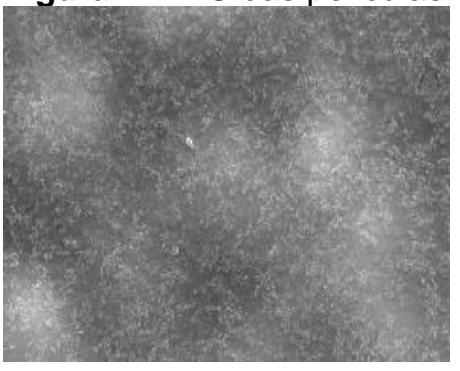

RF

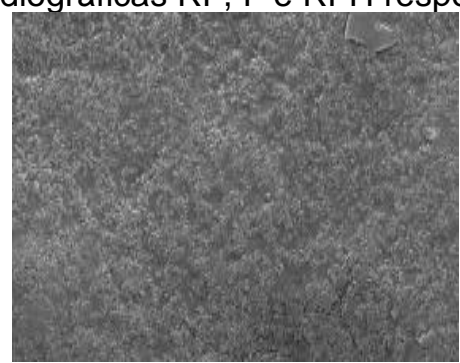

F

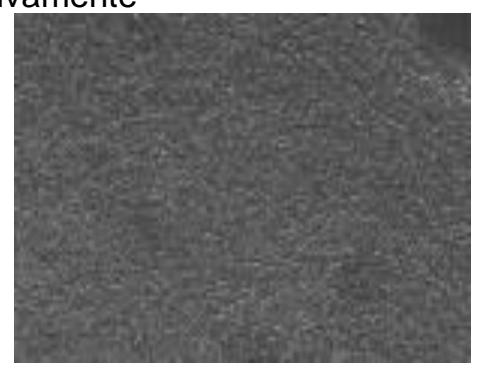

RFA

A imagem registrada na Figura 1 com a denominação $R F$, é aquela em que foi efetuado o procedimento de revelação e fixação. Nesta película de poliéster está presente o sal de prata, evidenciado pelos pontos esbranquiçados que se concentram de maneira variável na camada de gelatina. 
No procedimento denominado de fixação os sais de prata são removidos e, na superfície da película de poliéster se encontra de maneira predominante apenas a gelatina, que aparece na forma de uma granulação grosseira na imagem registrada na Figura 1 com a denominação $\mathrm{F}$.

Na película fixada (sal de prata removido) e mantida em ácido nítrico concentrado em ebulição, tem-se também a eliminação da gelatina e, a imagem resultante que foi registrada na Figura 1 com a denominação RFA, em que granulações esbranquiçadas e grosseiras estão ausentes, representa apenas o poliéster.

\subsection{Espectroscopia de energia dispersiva de raios $X$ (EDS)}

$\mathrm{Na}$ Tabela 1 estão às concentrações médias em porcentagem dos elementos presentes nas películas radiográficas reveladas e fixadas $(R F)$, fixadas $(F)$ e reveladas, fixadas e submetidas ao ácido nítrico concentrado em ebulição (RFA), obtidas através da EDS com os respectivos desvios padrões entre parênteses.

Tabela 1 - Composição da película obtida através da EDS

\begin{tabular}{crrr}
\hline Elemento & \multicolumn{1}{c}{$\mathbf{R F}(\%)$} & \multicolumn{1}{c}{$\mathbf{F}(\%)$} & \multicolumn{1}{c}{ RFA (\%) } \\
\hline $\mathrm{Ag}$ & $46,8(0,24)$ & $0,4(0,03)$ & $0,2(0,03)$ \\
$\mathrm{O}$ & $36,1(0,00)$ & $70,0(0,00)$ & $70,3(0,00)$ \\
$\mathrm{N}$ & $0,0(0,00)$ & $4,6(0,30)$ & $4,9(0,28)$ \\
$\mathrm{C}$ & $9,1(0,22)$ & $19,0(0,25)$ & $19,0(0,23)$ \\
$\mathrm{Si}$ & $6,6(0,06)$ & $4,1(0,04)$ & $3,8(0,04)$ \\
$\mathrm{S}$ & $0,0(0,00)$ & $0,7(0,02)$ & $0,6(0,02)$ \\
$\mathrm{Al}$ & $0,8(0,04)$ & $0,6(0,02)$ & $0,6(0,02)$ \\
$\mathrm{Cl}$ & $0,3(0,06)$ & $0,5(0,01)$ & $0,5(0,01)$ \\
$\mathrm{Cu}$ & $0,3(0,06)$ & $0,1(0,02)$ & $0,1(0,02)$ \\
\hline
\end{tabular}

Considerando as três películas estudadas (RF, F e RFA), observa-se que os elementos mais representativos são prata, oxigênio, nitrogênio, carbono e silício. A soma das porcentagens destes elementos atingem valores superiores a $98 \%$. A prata é o elemento mais abundante na película revelada e fixada. Na fixada (F) e fixada e submetida ao ácido nítrico em ebulição, as concentrações deste metal atingem valores muito baixos, o que demonstra que tais procedimentos não permitem a remoção total deste metal das películas.

Carbono e oxigênio estão presentes no poliester (MANO, MENDES, 1999). Carbono, oxigênio, nitrogênio e enxofre são encontrados em proteínas, que fazem parte da gelatina 
(MANO, MENDES, 1999). O enxofre pode ter sido incorporado às películas durante a fixação, pois faz parte das fórmulas do tiossulfato e sulfíto presentes no fixador.

É possível que o silício esteja presente na gelatina que é obtida a partir de peles e ossos de animais (ALVARES, TAVANO, 2009). Já o alumínio, possivelmente foi incorporado durante a fixação, pois é um dos elementos encontrados no alumen presente no fixador.

A presença de cloro, pode ser um indicativo de que o sal de prata presente nas películas seja o cloreto de prata. Não foram encontrados dados na literatura que relatem a origem da presença de cobre nas películas radiográficas estudadas, talvez seja uma impureza do ouro utilizado na metalização das películas antes de serem submetidas a FEG e EDS.

\subsection{Difração de raios $X$}

Foram realizados três ensaios de difração de raios $X$; sendo um deles após a película ter sofrido as etapas de exposição aos raios $X$ seguida de revelação e fixação (RF). Com esse procedimento, se estabeleceu as condições necessárias para que a prata e a gelatina estejam presentes na película de poliester. Após exposição à radiação $\mathrm{X}$, seguida apenas da fixação. Tal condição permitiu a eliminação da prata da película, restando a gelatina e o poliester $(F)$ e, após a película ter sido revelada, fixada e submetida ao ácido nítrico concentrado em ebulição (RFA). Tal processo, seria responável pela eliminação da gelatina e prata, restando apenas o poliester. A Figura 2 trás estes difratogramas.

Figura 2 - Difratogramas sobrepostos das películas radiográficas RF, F, RFA

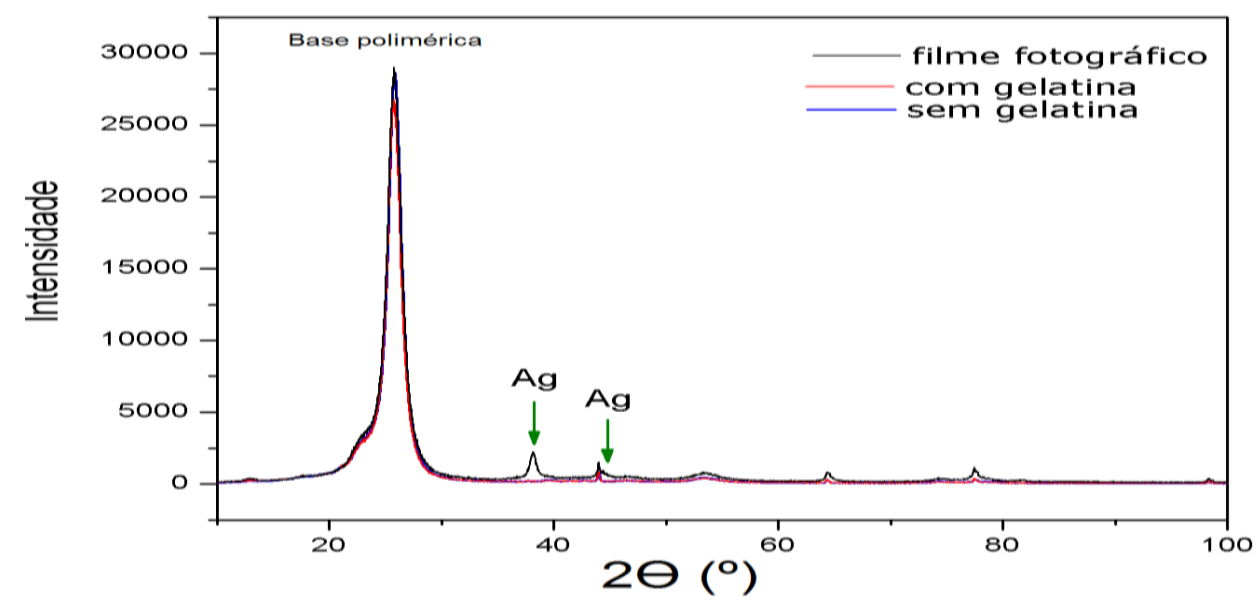


Na Figura 2, se observa que os picos referentes à prata estão presentes apenas no difratograma da película que sofreu os processos de exposição aos raios $\mathrm{X}$, seguido de revelação e fixação $(\mathrm{RF})$, que na figura está registrado como filme fotográfico.

Nos trabalhos de Morcali, Aktas e Yucel (2010) e Cui, Xionga e Lopes-Valdivieso (2011), são encontrados difratogramas onde os picos de difração atribuídos a prata se localiazam visualmente na mesma região do difratograma presente na Figura 2.

Outra observação é a presença de um pico intenso localizado a aproximadamente 24ํㅡㄹ nos difratogramas em que sais de prata estão presentes (RF), e também naquelas em que estes sais e a gelatina são removidos ( $F$ e RFA respectivamente), que na figura recebe as respectivas conotações de com e sem gelatina. Tal observação nos permite concluir que este pico é referente a base polimérica.

\subsection{Avaliação da mobilidade da prata}

O método de Tessier (TESSIER et al., 1979) é o mais citado e utilizado na literatura entre todos os métodos de extração sequencial e foi criado para a determinação de metais pesados em sedimentos (LÃ et al., 2003). Nesta avaliação, o interesse está focado nas condições variáveis das concentrações iônicas, $\mathrm{pH}$ e de oxidação/redução que permitem a lixiviação de metais e assim avaliar os possíveis danos ambientais quando da disposição inadequada destas películas.

$\mathrm{Na}$ contaminação ambiental, a exposição do material a determinadas condições permite a formação de lixiviados, cujas concentrações de metais podem ser comparadas com as de efluentes que podem ser lançados, direto ou indiretamente nos cursos d'água.

A Resolução CONAMA 430/11 traz os valores máximos permitidos (VMP) das condições padrões de lançamento de efluentes. Quando os valores são encontrados acima do VMP, este percolado possui potencial para causar efeitos tóxicos ao ambiente.

$\mathrm{Na}$ Tabela 2 são encontradas as concentrações em $\mathrm{mg} \mathrm{L}^{-1}$ de prata nos extratos obtidos via aplicação do método de Tessier e colaboradors (1979), as porcentagens de cada fração, as concentrações de prata lixiviadas por grama de película e o valor máximo permitico segundo a Resolução CONAMA 430/11. 
Tabela 2 - Concentrações médias de $\mathrm{Ag}$ em $\mathrm{mg} \mathrm{L}^{-1}$ encontradas nas frações lixiviadas em $\mathrm{pH}=7,0 \mathrm{e}$ $\mathrm{pH}=5,0$; aplicação de um redutor e oxidante, porcentagem de cada fração, concentrações de prata em mg por grama de película e o valor máximo permitido (VMP) de acordo com a Resolução CONAMA 430/11

\begin{tabular}{ccccc}
\hline Extração & $\mathbf{A g}\left(\mathbf{m g ~ L}^{-1}\right)$ & $\%$ & $\mathbf{m g ~ A g ~ ~ ^ { - 1 }}$ & $\mathbf{V M P} \mathbf{( m \mathbf { g ~ L } ^ { - 1 } )}$ \\
\hline $\mathrm{pH} 7$ & 4,0 & 3,7 & 0,03 & \\
$\mathrm{pH} 5$ & 0,8 & 0,7 & 0,002 & \\
Redutor & 3,1 & 2,8 & 0,006 & 0,1 \\
Oxidante & 101,3 & 92,8 & 1,04 & \\
Soma & 109,2 & 100 & 1,078 & \\
\hline
\end{tabular}

$\mathrm{Na}$ extração em pH 7, utilizou-se solução aquosa de $\mathrm{MgCl}_{2}$ a 1 mol L-1, e no lixiviado, encontrou-se concentrações de prata quarenta vezes maiores que o VMP. Valores de pH da água presentes no meio ambiente próximos a este valor foram encontrados em vários trabalhos (SILVA et al. 2008, GOLOMBIESKI et al 2005, GUERRA et al. 2006).

Em pH 5, a extração foi realizada utilizando-se uma solução tampão de ácido acético/acetato. No lixiviado obtido em tal condição de $\mathrm{pH}$, a concentração de prata atingiu valores oito vezes maiores que o VMP. Tal valor de $\mathrm{pH}$ se faz presente no meio ambiente como no caso das chuvas, que atualmente são comuns num pH geralmente menor que 5 (HUANG et al., 2008, LEAL, FONTENELE, PEDROTTI, 2004; MIGLIAVACCA, TEIXEIRA, MACHADO, 2005; TENORIO, COSTA, 2011). Tomando-se em consideração apenas a acidez, a disposição destas películas em aterros sanitário, lixões, trariam riscos menores, pois geralmente os valores de $\mathrm{pH}$ encontrados em percolados destes sistemas de deposição de resíduos sólidos são alcalinos (BRITO et al.,2010, MORAIS, SIRTORI, PERALTA-ZAMARO, 2006).

Outros autores removeram prata de películas radiográficas utilizando ácidos como, Syed et al. (2002) que o fizeram com ácido oxálico $0,11 \mathrm{~mol} \mathrm{~L}^{-1}$ a $97^{\circ} \mathrm{C}$, Morcali, Aktas e Yucel (2010) com a aplicação ácido nítrico $1 \mathrm{~mol} \mathrm{~L}^{-1}$ a $85^{\circ} \mathrm{C}$.

A utilização de um meio redutor obtido a partir do contato de películas radiográficas com cloreto de hidroxilamina permitiu a lixiviação de prata numa concentração 31 vezes maior que o VMP da Resolução CONAMA 430/11. Tal condição está presente em aterros sanitários, lixões, após alguns meses ou um ano da deposição dos resíduos sólidos (BAIRD, 2002). 
Já a presença de um meio oxidante, que em águas naturais o mais importante é o oxigênio (BAIRD, 2002) e que nessa extração é representado pela mistura de $\mathrm{HNO}_{3}$ e $\mathrm{H}_{2} \mathrm{O}_{2}$, a prata foi extraída numa concentração próxima a mil vezes maior que o VMP.

A utilização de outro meio oxidante, no caso uma mistura de ácido clorídrico/ácido nítrico na proporção de 3:1 foi utilizado por Petter, Veit e Bernardes (2015) para lixiviar prata, de placas de circuitos impressos de celulares.

A distribuição das concentrações de prata extraídas em $\mathrm{pH} 7,5$, meio redutor e oxidante está presente na figura 3.

Figura 3 - Distribuição das concentrações de prata nas frações lixiviadas em $\mathrm{pH}=7, \mathrm{pH}=5$, aplicação de um redutor e oxidante

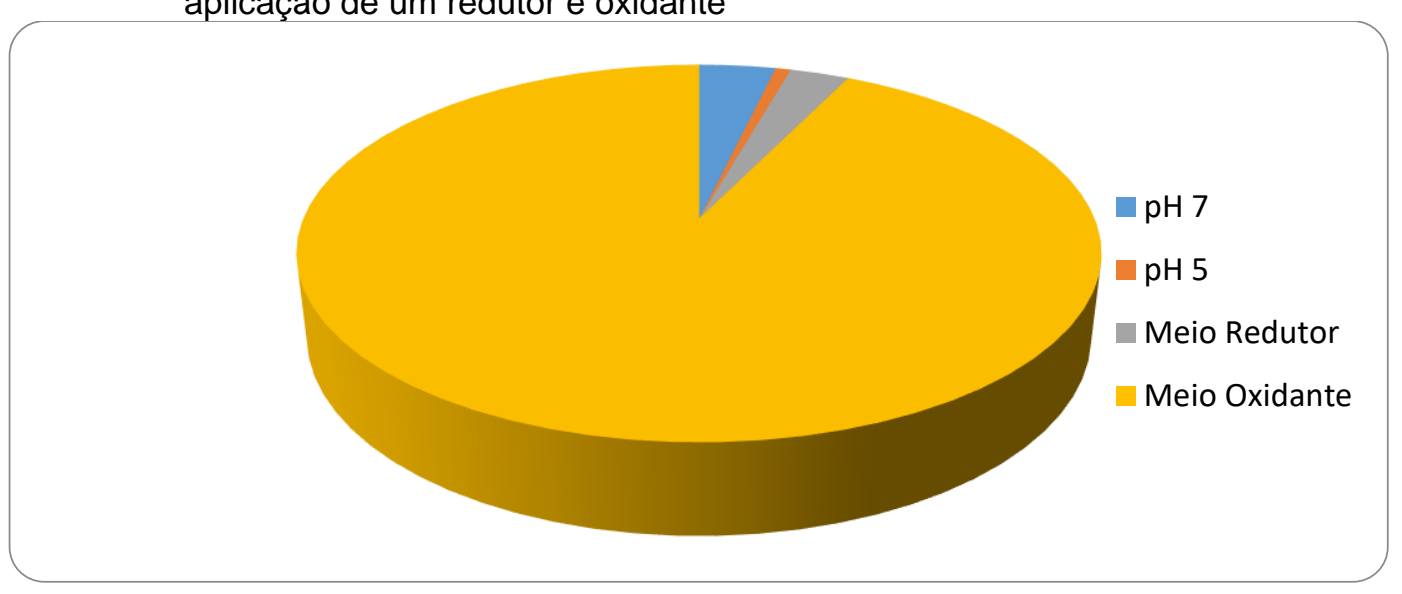

Pela análise dos dados presentes na tabela 2 e figura 3 se observa que nas películas radiográficas periapicais de uso odontológico, a prata se concentra basicamente na fração lixiviável via ação de um oxidante, o que corresponde a aproximadamente $93 \%$ da prata lixiviada (Tabela 2). Em menores concentrações estão aquelas lixiviadas em presença de $\mathrm{pH}=7$ seguida da ação de um meio redutor e $\mathrm{pH}=5$.

\section{CONCLUSÕES}

Com a microscopia eletrônica de varredura por efeito de campo (FEG) foi possível verificar diferenças superficiais entre as películas que apresentavam sais de prata, camada de gelatina ou apenas o poliéster. Através da espectrometria de energia dispersiva de raios $X$ (EDS) determinou-se as concentrações dos elementos presentes nas películas, sendo que a somatória das concentrações de prata, oxigênio, nitrogênio, carbono e silício correspondem a aproximadamente $98 \%$ da massa dos elementos presentes. Enxofre, alumínio, cobre e cloro também foram encontrados em baixas concentrações. Pela difração 
de raios $X$ se observou picos referentes a prata e um pico intenso a aproximadamente $24^{\circ}$ que foi atribuído a base polimérica. A avaliação da mobilização e disponibilidade da prata a partir do método de Tessier e a comparação com os VMP do CONAMA 430/11 demonstra os riscos potenciais de lixiviação deste metal em condições presentes no meio ambiente, já que ela pode ser lixiviada em pHs 7, 5, presença de um redutor e de maneira intensa em presença de um oxidante.

\section{REFERÊNCIAS}

ALVARES, L.C., TAVANO, O. Curso de radiologia em odontologia. 5. ed. São Paulo: Santos Editora, 2009. 274 p.

BAIRD, C. Química ambiental. Porto Alegre: Bookmn., 2002. 662p.

BOSSO, S.T.; ENZWEILER, J. Ensaios para determinar a (bio) disponibilidade de chumbo em solos contaminados: revisão. Química Nova, v.31, n. 2, p.394-400, 2008.

https://doi.org/10.1590/S0100-40422008000200036.

BRASIL, CONSELHO NACIONAL DO MENIO AMBIENTE- Resolução CONAMA, 430/2011. Disponível em: http://www.mma.gov.br/port/conama/legiabre.cfm?codlegi=646. Acesso em: 15 ago. 2012.

BRITO, N. N.; BROTA, G. A.; DOS SANTOS, E. M.; SILVA, N. B.; PELEGRINI, R. T.; PATERNIANI, J. E. S. Ensaios toxicológicos com sementes para avaliação de tratamento do chorume por filtração lenta e fotocatálise. HOLOS Environment, v.10, n.2, p.139-152, 2010. http://dx.doi.org/10.14295/holos.v10i2.2469.

CUI, Y., XIONG, T.; LOPEZ-VALDIVIEZA, A.; Silver sulfide leaching with a copper-thiosulfate solution in the absence of ammonia. Rare Metals, v.30, n.2, 9.105-109, 2011.

https://doi.org/10.1007/s12598-011-0206-8.

CRYSTALLOGRAPHY Open Database. Disponível em: http://www.crystallography.net/. Acesso em: set. 2015.

FREITAS, A. de., ROSA, J. E.; SOUZA, I. F. E. Radiologia odontológica. 6. ed. São Paulo: Artes Médicas, 2004. 833 p.

FREITAS, A. de., VAROLI, O. J., TORRES, F. A. Técnicas radiográficas intrabucais. São Paulo: Artes Médicas, 2000. 748p.

GOLOMBIESKI, J. I.; MARCHEZAN, E.; MONTI, M. B.; STORCK, L.; CAMARGO, E. R.; DOS SANTOS, F. M. Qualidade da água no consórcio de peixes arroz irrigado. Ciência Rural, v.35, n. 6, 2005, p 1263-1268. https://doi.org/10.1590/S0103-84782005000600006.

GUERRA, N. M. M.; OTÊNIO, M. H; SILVA, M. E. Z.; GUILHERMETTI, M.; NAKAMURA, C. V.; NAKAMURA-UEDA, T.; DIAS FILHO, B.P. Ocorrência de Pseudomonas Aeruginosa em água potável. Acta Scientiarum Biological Sciences, v. 28, n.1, 2006, p. 13-18.

https://doi.org/10.4025/actascibiolsci.v28i1.1053

HUANG, K.; ZHUANG, G.; XU, C.; WANG, Y.; TANG, A. The chemistry of the severe acid precipitation in Shangai, China. Atmospheric Research, v.89, p.149-160, 2008.

https://doi.org/10.1016/j.atmosres.2008.01.006. 
KUYA, M. Recuperação de prata de radiografias: uma experiênicia utilizando recursos caseiros. Química Nova, v.16, n.5, p. 474-476, 1993.

LÃ, O. R.; BARRA, C.M.; SOBRINHO, N .M .B .do A.; MAZUR, N.; VELLOSA, A. C. X. Avaliação dos métodos de extração sequencial de Tessier, Keller e Miller na determinação de ferro nativo cem três tipos de solos: Orgânico, Brunizem e Latossolo. Química Nova, v. 26, n. 3, p.323-330, 2003. https://doi.org/10.1590/S0100-40422003000300007.

LEE, J.D. Química Inorgânica não tão concisa. São Paulo: Edgard Blucher, 1999. p.

MANO, E.B., MENDES, L. C. Introdução a polímeros. 2. ed. São Paulo: Editora Edgard Blucher Ltda, 1999. $191 \mathrm{p}$.

MORAIS, J. L.de.; SIRTORI, C.; PERALTA-ZAMORA, P.G. Tratamento de chorume de aterro sanitário por fotocatálise heterogênea integrada a processo biológico convencional. Química Nova, v. 29, n.1, p.20-23, 2006. http://dx.doi.org/10.1590/S0100-40422006000100005.

PASLER, F. A. Radiologia odontológica. 3. ed. Rio de Janeiro: Médica e Científica, 1999. 457p.

LEAL, T. F. M., FONTENELE, A. P. G., PEDROTTI, J. J. Composição majoritária de águas de chuva no centro da cidade de São Paulo. Química Nova, v.27, n. 6, p.855-861, 2004.

http://dx.doi.org/10.1590/S0100-40422004000600003.

MIGLIAVACCA, D. M., TEIXEIRA, E. C., MACHADO, A. C. de M. Composição química da precipitação atmosférica no Sul do Brasil: estudo preliminar. Química Nova, v.28, n.3, p.371-379, 2005. http://dx.doi.org/10.1590/S0100-40422005000300002,

MORCALI, H.; AKTAS, S.; YUCEL, O. Silver recovery from waste radiographic films using different methods. The Minerals, Metals \& Materials Society, v.3, p.473-478, 2010.

https://doi.org/10.1179/cmq.2010.49.2.147

PETTER, P. M. H., VEIT, H .M., BERNARDES, A.M. Leaching of gold and silver from printed circuit board of mobile phones. Metallurgy and Materials, v. 68, n.1, p.61-68, 2015. https://doi.org/10.1016/i.wasman.2013.10.032.

SILVA, A. E. P.; ANGELIS, C. F.; MACHADO, L. A. T.; WAICHMAN, A. V. Influência da precipitação na qualidade da água do Rio Purus. Acta Amazônica, v.38, n..4, 2008, p 733-742. https://doi.org/10.1590/S0044-59672008000400017.

SYED, S.; SURESHAB, S.; SHARMAA, L. M.; ASAYED, A. Clean technology for the recovery of silver from processed radiographic films. Hidrometallurgy, v. 63, n.3, p. 277-280, 2002. https://doi.org/10.1016/S0304-386X(02)00003-8.

TENORIO, A. M.; COSTA, W. Um estudo da deposição de íons e matéria orgânica por meio das precipitações pluviométricas. Acta Scientiarum Technology, v. 33, n.4, p.457-463, 2011. ttps://doi.org/10.4025/actascitechnol.v33i4.7526

TESSIER, A., CAMPBELL, P. G. C., BISSON, M. Sequential extraction procedure for the speciation of particulate trace metals. Anal.chem., v. 51, p.844-851, 1979.

https://doi.org/10.1021/ac50043a017

WHAITES, E. Princípios de radiologia odontológica.4. ed. Rio de Janeiro: Elsevier Editora Ltda, 2007. 408 p. 